\title{
GnRH analog is ineffective in increasing adult height in girls with puberty onset after 7 years of age: a systematic review and meta-analysis
}

\author{
I A Franzini', F M Yamamoto', F Bolfi', S R Antonini ${ }^{2}$ and V S Nunes-Nogueira1 \\ 'Department of Internal Medicine, São Paulo State University (UNESP), Medical School, Botucatu, Sao Paulo, Brazil \\ and ${ }^{2}$ Department of Pediatrics, Ribeirao Preto Medical School, University of Sao Paulo, Ribeirao Preto, Sao \\ Paulo, Brazil
}

\author{
Correspondence \\ should be addressed \\ to V S Nunes-Nogueira \\ Email \\ vsnunes@fmb.unesp.br
}

\begin{abstract}
Objective: We assessed the effectiveness of puberty blockade with a gonadotropin-releasing hormone (GnRH) analog in increasing adult height (AH) in girls with puberty onset between 7 and 10 years of age.

Methods: We performed a systematic review and included controlled studies in which girls with early puberty (EP) were assigned to the $\mathrm{GnRH}$ analog or no treatment groups. The primary outcome analyzed was $\mathrm{AH}$. Search strategies were applied to the MEDLINE, EMBASE, LILACS and CENTRAL databases.

Results: We identified 1514 references, and six studies fulfilled our eligibility criteria. Two studies were randomized and four were not randomized. At the baseline of each trial, height, chronological age, bone age, predicted AH (PAH) and target height (TH) were equal between the groups. All studies used intramuscular triptorelin every 28 days in the intervention groups. The mean duration of the therapy was 2 years. Meta-analysis of $\mathrm{AH}$ among the six studies (comprising 332 girls) showed no significant difference between the groups (mean difference $=0.50 \mathrm{~cm}$, $95 \%$ confidence interval $=-0.72$ to $\left.1.73 \mathrm{~cm}, I^{2}=0 \%\right)$. In a sub-group analysis based on $\mathrm{PAH}(<155 \mathrm{~cm}$ and $<\mathrm{TH} ;<\mathrm{TH}$, but $>155 \mathrm{~cm}$ and equal to $\mathrm{TH}$ ), there was no difference in average $\mathrm{AH}$ between the groups. The quality of evidence according to the Grading of Recommendations Assessment, Development and Evaluation approach was low. Conclusion: We found no evidence from controlled experimental and observational studies that compared with no treatment, the use of GnRH analogs improved AH in girls with EP.

\section{Introduction}

Early puberty (EP) is defined as puberty occurring at the normal age of pubertal development, where the appearance of Tanner stage 2 or 3 , with or without sexual hair, which is associated with advanced bone age (BA), accelerated growth velocity and activated hypothalamicpituitary-gonadal axis, would occur during the first half of the normal distribution of pubertal onset $(1,2)$. Although various age intervals have been mentioned in the literature for EP, based on the report by Lebrethon and
Bourguignon (3), Mul et al. (1) proposed to consider EP as puberty onset in girls between 8 and 10 years of age in Europe and at 7-9 years of age in the United States.

Conversely, precocious puberty (PP) is defined as the appearance of secondary sexual characteristics before 8 years of age in girls and before 9 years of age in boys. In a historical series of girls with severe forms of PP, lack of treatment has been associated with a mean adult height (AH) of $152 \mathrm{~cm}$ and loss of height of 
approximately $10 \mathrm{~cm}$ (4). Because of these data, parents and pediatricians are concerned about the potential loss of height in girls with EP.

However, because EP is considered as normal puberty development, girls with this diagnosis are not expected to have a reduction in $\mathrm{AH}$ as well as other maladjustments found in some girls with PP. An observational study following the growth and pubertal development of 104 Thai girls with EP in Thailand reported that at the final visit, these girls attained $\mathrm{AH}$ according to their parental height (5).

In some girls, EP can be accompanied with rapid pubertal development, reaching Tanner stage 3 before 10 years of age, which is significantly earlier than the median age for reaching this stage in normal girls $(11.9 \pm 1.0$ years) (6). Some authors consider this situation, i.e., combined early and fast puberty, to be a state of so-called sexual precocity for age, a condition that is very similar to central PP (CPP) and with the possibility of reduction in $\mathrm{AH}$, and a form of psychosocial embarrassment for the girls (7). Meanwhile, Lazar et al. (8) analyzed data on 126 girls with that diagnosis and showed that girls treated with a gonadotropin-releasing hormone (GnRH) analog and untreated girls achieved a similar mean $\mathrm{AH}$, which was not significantly different from their respective mean target heights (THs).

At the same time, the search for puberty blockade in healthy girls who have just had their eighth birthdays and whose pubertal evolution is compatible with EP is common in clinical practice. Many physicians are also concerned that these children may not reach their $\mathrm{TH}$ range $(\mathrm{TH} \pm 1.5$ standard deviation (s.D.)), and consequently, many girls with normal puberty considered as having EP have received puberty blockade with GnRH analogs worldwide.

Thus, under the hypothesis that there is no difference on AH with the usage of GnRH analogs, we assessed whether puberty blockade with GnRH analogs is effective in increasing $\mathrm{AH}$ in girls with EP compared with that in those undergoing no treatment.

\section{Methodology}

A systematic review was conducted following the Cochrane Handbook for Systematic Reviews of Interventions (9) and reported according to the Preferred Reporting Items for Systematic Reviews and Meta-Analyses (10). Its protocol was registered in the International Prospective Register of Systematic Reviews, under CRD42017064599.

\section{Criteria for eligibility}

We included randomized and non-randomized controlled studies that adopted the PICO ( $\mathrm{P}=$ Patients, $\mathrm{I}=$ Intervention, $\mathrm{C}=$ Comparison and $\mathrm{O}=$ Outcomes) structure noted below:

- Patients: We considered girls as having EP based on the appearance of Tanner stage 2 or 3 between 7 and 10 years of age, with or without sexual hair and associated with some evidence of activation of the hypothalamic-pituitary-gonadal axis.

- Intervention: The intervention group comprised girls whose puberty was blocked using a long-action GnRH analog in its different forms (triptorelin, nafarelin, leuprolide, goserelin and buserelin).

- Comparison: Placebo or no treatment.

- Outcomes: The primary outcome analyzed was the average AH. Secondary outcomes were whether the girls reached their TH range, pubertal height gain, adverse events, quality of life and psychosocial impact.

\section{Exclusion criteria}

We excluded studies that included girls with some organic conditions identified as the cause of PP, clinical signs of rapidly progressing puberty (a change in the Tanner stage in $<3$ months) or puberty onset before 7 years and studies in which the groups were significantly different in terms of height, chronological age (CA), BA, TH and predicted $\mathrm{AH}(\mathrm{PAH})$ at the baseline visit.

\section{Identification of the studies}

Four general and adaptive search strategies were created for the electronic health databases: EMBASE (by Elsevier, 1980-2018), MEDLINE (by PubMed, 1966-2018), LILACS (by Virtual Health Library, 1982-2018) and Registry of Controlled Clinical Studies of the Cochrane Collaboration (CENTRAL-Cochrane; Supplementary data, see section on supplementary data given at the end of this article). There was no restriction regarding language or year of publication. Databases were searched on May 25, 2016, and updated on January 25, 2018.

Eligible studies were also surveyed in the Trip Medical Database, SCOPUS, Web of Science and CINAHL. We also looked for unpublished studies among Ph.D. or master degree theses, ClinicalTrials.gov website and Brazilian Registry of Clinical Trials (ReBec).

We used the Endnote software for downloading all references, removing duplicates and facilitating the selection process. 


\section{Assessment of eligibility of the studies}

Two reviewers (I A F and F B) independently selected the titles and abstracts identified during the literature search. Potentially eligible studies for inclusion in the review were read completely and subsequently assessed in terms of appropriateness of the proposed PICO structure. Whenever there was disagreement in the selection process, a consensus was reached by discussion with the project coordinator (V S N N).

For the studies selected for inclusion, both reviewers used a standardized extraction form so that all information regarding each study (number of patients, average age, study design, inclusion and exclusion criteria, intervention nature, outcomes analyzed, monitoring time and risk of bias) might be computed.

\section{Risk of bias}

For each selected randomized and prospective nonrandomized clinical study, the risk of bias was evaluated according to the criteria described in the Cochrane Reviewers Handbook (9), which considers seven domains: the process of randomization, concealing allocation, blinding of participants and researchers, blinding of outcome assessors, whether the losses were included in the final analysis, selective reporting of outcomes and others.

For each selected observational study, the risk of bias was evaluated according to the criteria described by the Newcastle-Ottawa Scale (NOS) for case-control studies, which considers three domains: selection (four items), comparability (one item) and exposure (three items) (11).

\section{Synthesis and analysis of data: meta-analysis}

Similar outcomes measured in at least two studies were plotted in a meta-analysis using the software Review Manager 5.3 (the Cochrane Community). Continuous data are expressed as means and s.D.s. Differences between means with 95\% CIs were used as an estimate of the intervention effect. We chose the random effect model as the analytic model in the meta-analysis. The inverse variance method was used for weighing the estimates of the effect among the studies included. Inconsistencies among the study results were verified by visual inspection of the forest graph (absence of overlap of CIs of the estimates of the effects in the individual studies) and by the Higgins inconsistency test in which $I^{2}>50 \%$ indicated a moderate probability of heterogeneity.

\section{Quality of the evidence}

The quality of evidence of estimation of the effect of the intervention on outcomes that could be plotted in the meta-analysis was generated in accordance with the Grading of Recommendations Assessment, Development, and Evaluation (GRADE) Working Group (12).

\section{Results}

\section{Selection of studies}

The search strategies yielded 1514 references; after removing duplicates, 1382 studies remained. We selected 33 studies, with a high probability of inclusion in this review, for complete reading (Fig. 1). After completely reading these references, six studies met our eligibility criteria and therefore were included in this review $(2,8$, $13,14,15,16)$. A total of 27 studies were excluded for the following reasons: six studies did not have controls; two used historical control groups $(17,18)$; five were retrospective studies on CPP $(19,20,21,22,23)$; in two studies, the control group consisted of patients with normal evolution at puberty $(24,25)$; in three studies on $\operatorname{EP}(26,27,28)$ and six studies on CPP, the control group had a predicted AH significantly greater than that in the intervention group $(29,30,31,32,33,34)$ and three studies on CPP included girls with puberty onset at $<7$ years of age $(35,36,37)$.

The six studies included involved a total of 332 girls. Two studies were randomized $(2,16)$, three were non-randomized prospective controlled studies $(13,14$, 15) and one was an observational controlled study (8). Eligibility criteria for the included studies and baseline characteristics of study participants are presented in Tables 1 and 2, respectively.

At the baseline of each trial, height, CA, BA, PAH and $\mathrm{TH}$ were not statistically different between the intervention and comparison groups. In two studies, the included girls presented with mean PAH of $<155 \mathrm{~cm}$ and $<$ mean TH at diagnosis $(8,16)$. In the study conducted by Chiavaroli et al. (13), the patients had mean $\mathrm{PAH}<$ mean $\mathrm{TH}$, but $>155 \mathrm{~cm}$. In three studies $(2,14,15)$, the PAH was equal to TH. PAH was calculated by the method used by Bayley and Pinneau (38).

Regarding the type of GnRH agonist, all studies used intramuscular triptorelin every 28 days in the intervention group, whereas the comparison groups did not receive treatment. The mean duration of intervention was 2 years in most studies, and follow-up lasted until achievement of $\mathrm{AH}$. 


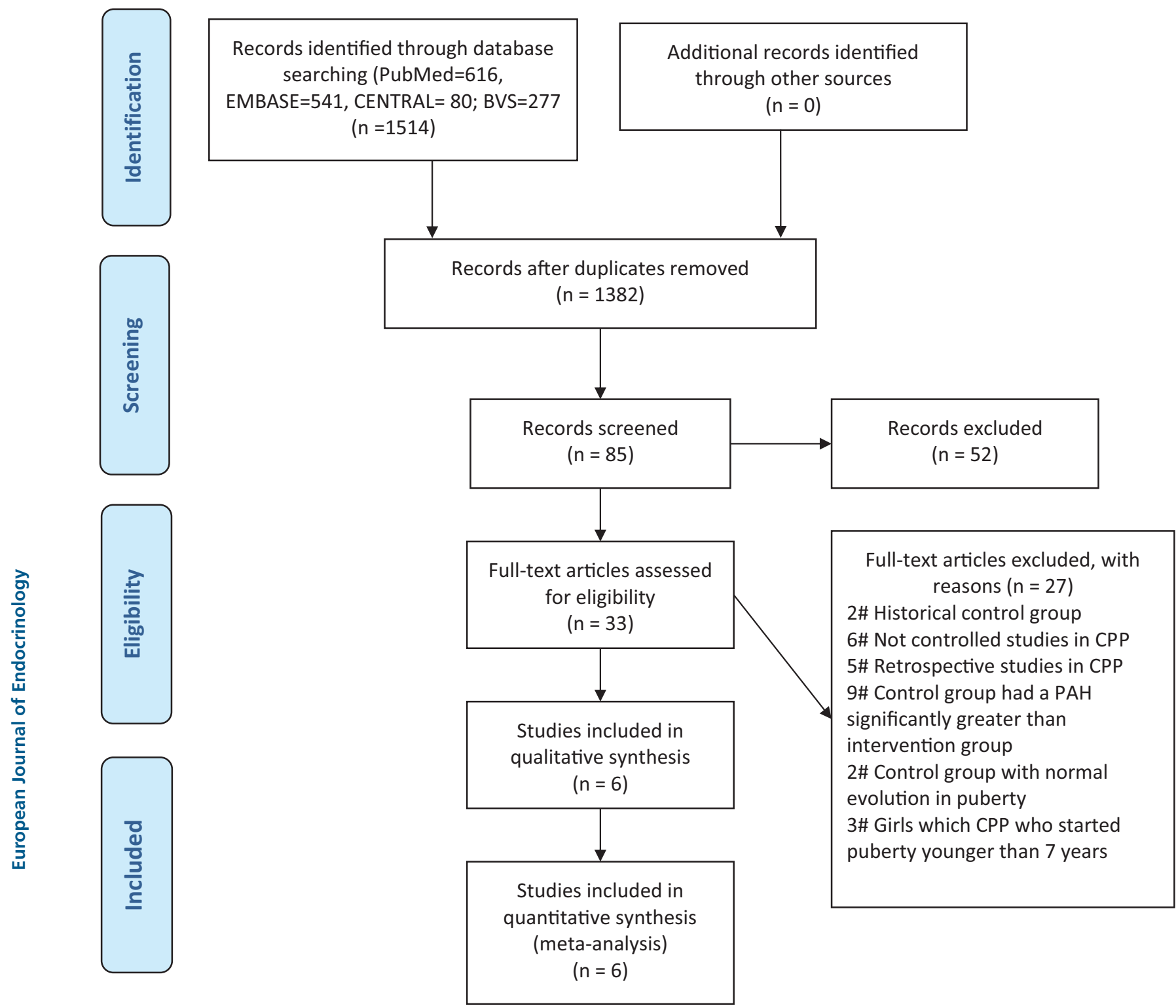

Figure 1

Flowchart for identifying eligible studies.

\section{Risk of bias among the included studies}

For randomized and non-randomized prospective studies, the risks of bias in the five included studies are presented in Fig. 2. For the observational study, applying NOS, Lazar et al. (8) achieved three stars for the selection domain, two for comparability and three for exposure, resulting in a total of eight stars (maximum nine).

\section{Meta-analysis}

The only outcomes that could be plotted in the metaanalysis were $\mathrm{AH}$ and final BMI. Meta-analysis of $\mathrm{AH}$ among the six studies showed no significant difference between the groups (mean deviation $(\mathrm{MD})=0.50 \mathrm{~cm}, 95 \%$ $\mathrm{CI}=-0.72$ to $\left.1.73 \mathrm{~cm}, I^{2}=0 \%\right)$. We performed a sub-group analysis according to PAH $(<155 \mathrm{~cm}$ and $<\mathrm{TH},<\mathrm{TH}$ but $>155 \mathrm{~cm}$ and equal to $\mathrm{TH}$ ); in all these analyses, there were no differences in $\mathrm{AH}$ between the groups (Fig. 3).

Three studies assessed BMI at discontinuation of the GnRH treatment and at the final study visit. In the studies by Chiavaroli et al. (13) and Lazar et al. (8), at discontinuation of the suppressive treatment, the treated girls showed higher BMI than the untreated girls; however, during $\mathrm{AH}$ measurement, no significant difference was 

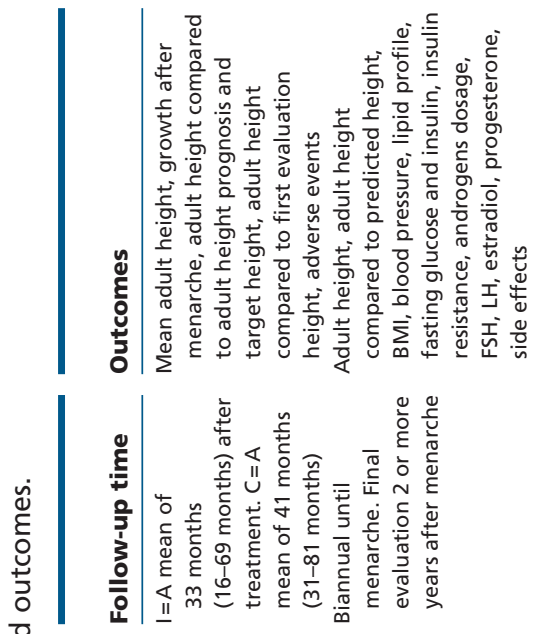

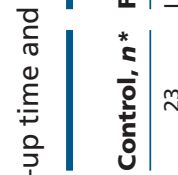

하을

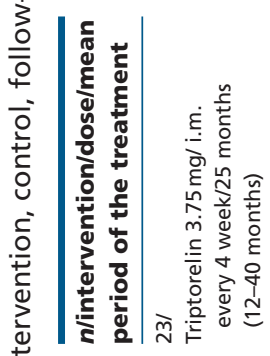

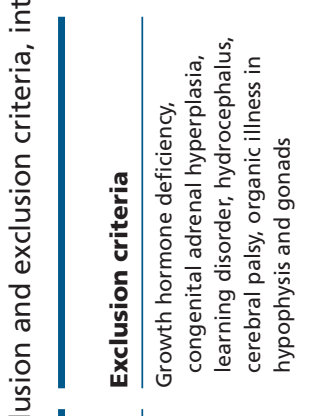

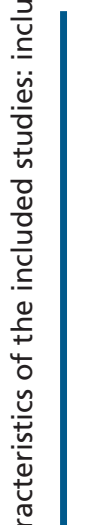
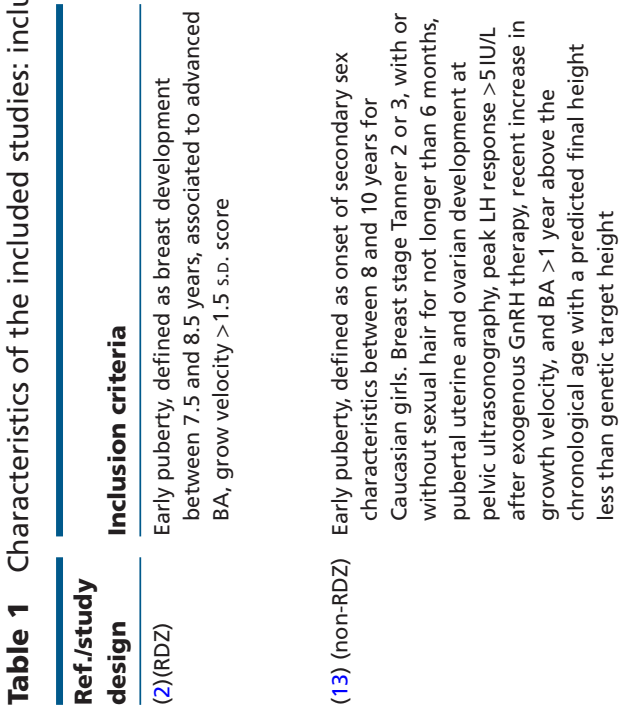
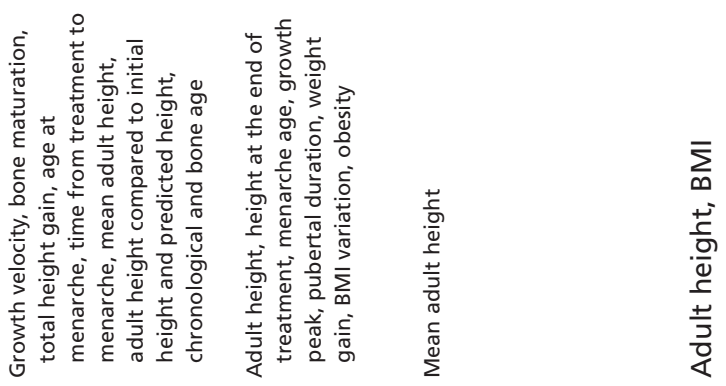

$\bar{\sum}$
0
5
$\frac{5}{5}$
$\frac{0}{\bar{d}}$
$\frac{5}{5}$
$\frac{3}{4}$
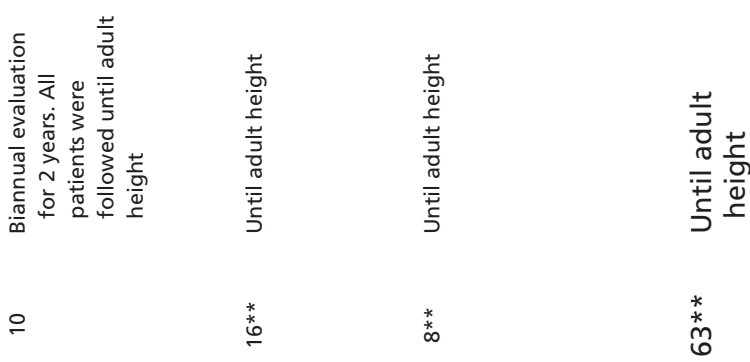

$\underset{\infty}{*}$

丞
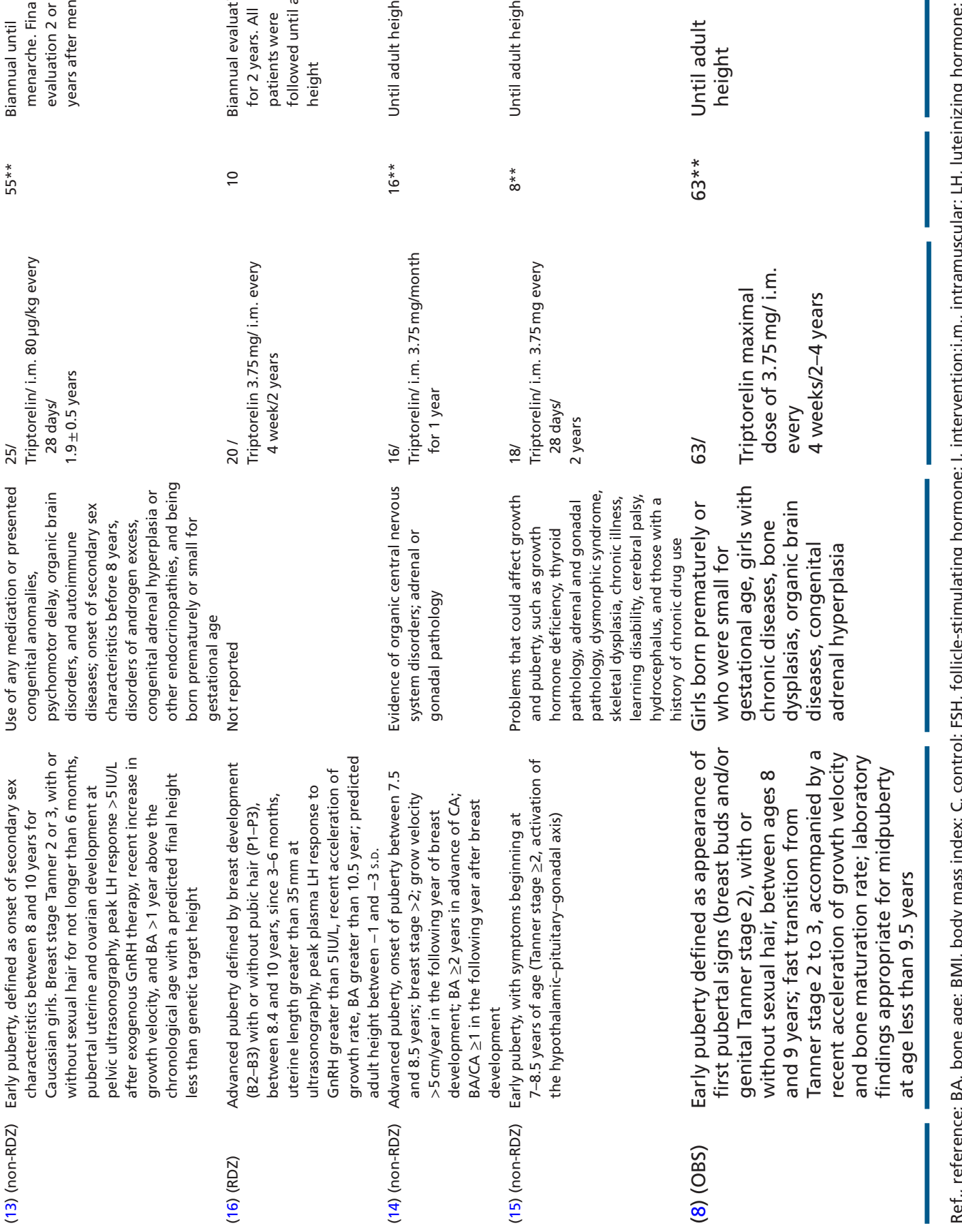

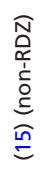

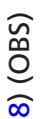

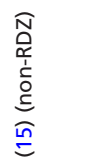


found between the two groups. Llop-Vinolas et al. (14) found no significant differences in body fat mass, BMI and weight during treatment and at the end of the study. A meta-analysis of BMI at the final visit did not show any significant difference between the groups ( $\mathrm{MD}=0.01,95 \%$ $\mathrm{CI}=-0.35$ to $\left.0.37, I^{2}=40 \%\right)$.

\section{Results of outcomes that could not be plotted in the meta-analysis}

No study assessed the social impact and quality of life of the girls studied. Chiavaroli et al. (13) assessed the presence of polycystic ovary syndrome (PCOS). For both criteria used (Androgen Excess Society (AES, 2006) and Rotterdam, 2003), the frequency of PCOS was higher in the treatment than in the comparison groups (36 and $14.5 \%$; relative risk $(\mathrm{RR})=2.48,95 \% \mathrm{CI}=1.08-5.66$ and 56 and $23.6 \% ; \mathrm{RR}=2.37,95 \% \mathrm{CI}=1.32-4.27$, respectively).

Only Lazar et al. (8) evaluated the number of girls who reached their $\mathrm{TH}$ range, with a non-significant difference; $70 \%$ of the treated and $67 \%$ of untreated girls achieved $\mathrm{AH}$ within or above their $\mathrm{TH}$ range \pm 0.5 s.D.

\section{Quality of evidence}

Applying GRADE to the primary outcome (AH), it was necessary to rate the quality of evidence in two domains: risk of bias and imprecision. The same results were observed as that for the frequency of PCOS. Therefore, the quality of evidence for these two items was low and very low, respectively (Supplementary Table 1).

\section{Discussion}

To present the best available evidence for helping clinicians in making decisions, we conducted a systematic review for comparing the effect of no treatment with the use of GnRH analogs on AH in girls with EP.

Six studies (total, 332 girls) were included. Metaanalysis of $\mathrm{AH}$ showed $\mathrm{MD}$ of $0.5 \mathrm{~cm}$ and $95 \% \mathrm{CI}$ of -0.72 to $1.73 \mathrm{~cm}$, i.e., there was no significant difference in $\mathrm{AH}$ between the groups studied. Even in the three studies in which the girls had $\mathrm{PAH}<\mathrm{TH}$, there were no differences in AH (MD $=0.59,95 \% \mathrm{CI}=-0.86$ to $\left.2.04, I^{2}=0 \%\right)$.

Although we were unable to assess the number of children in each group who attained their TH range using meta-analysis, it is important to note that, except for the study by Chiavaroli et al. (13) in the other included studies, the average $\mathrm{AH}$ of girls in the treatment and control groups was similar to or greater than TH (Table 2).
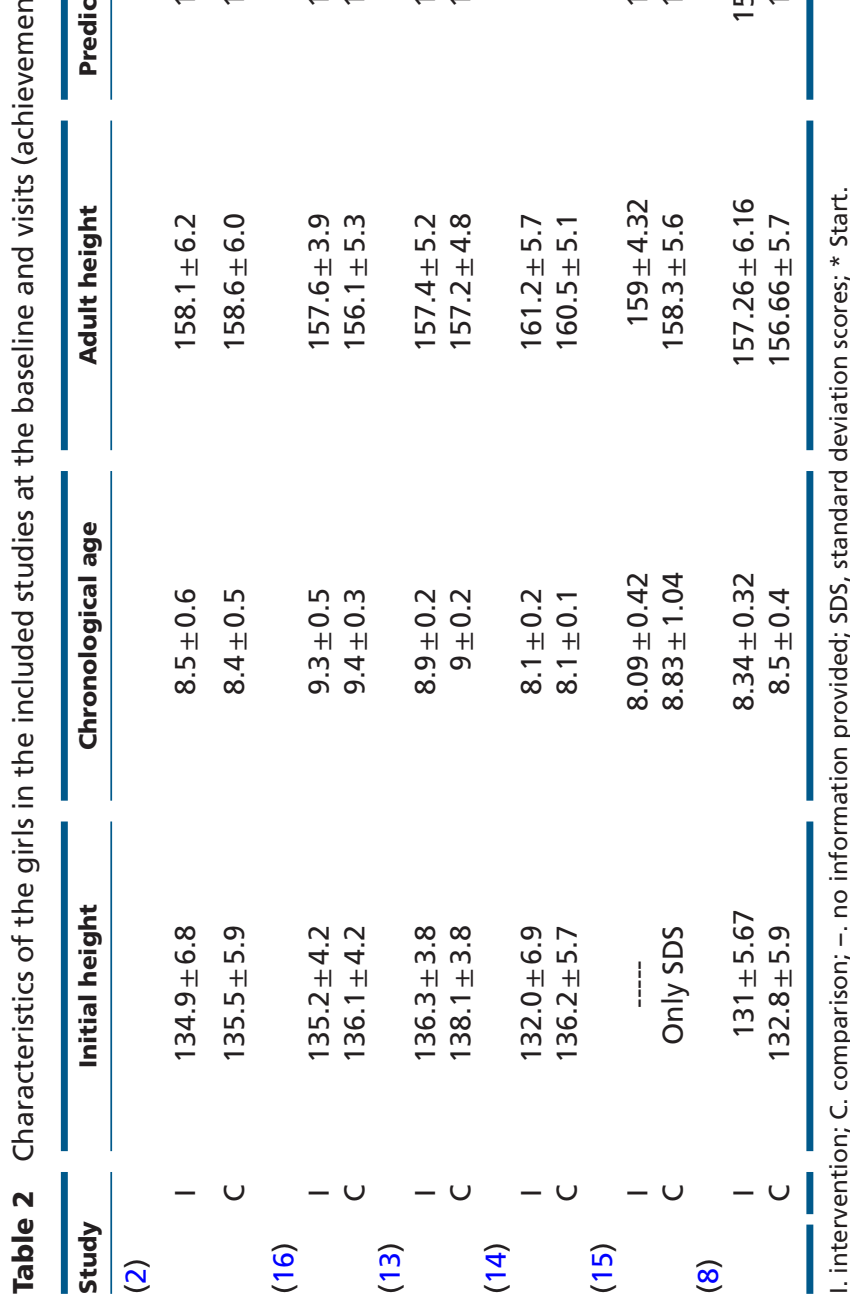


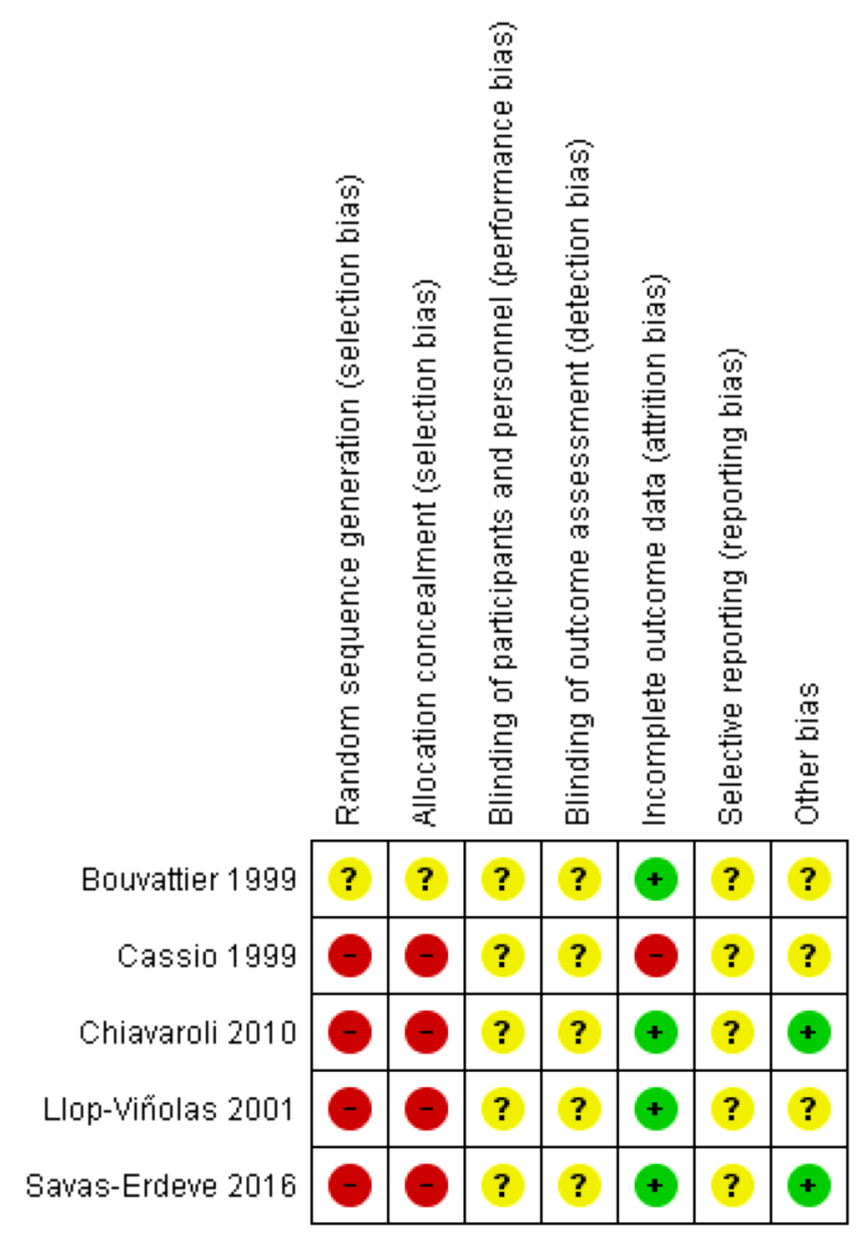

\section{Figure 2}

Risk of bias summary. Review authors' judgments about each risk of bias item for each included study. Yellow circles indicate uncertainty. Green and red circles indicate low and high risk of bias, respectively. A full colour version of this figure is available at https://doi.org/10.1530/EJE-18-0473.

Three studies analyzed BMI of the participants at the final visit. Although there was no significant difference between the intervention and control groups, Chiavaroli et al. (13) reported that GnRH treatment tended to increase the body weight and significantly increased the risk of PCOS during adolescence. However, as this study was non-randomized and used a control group in which parents requested their daughters not be treated, causality could not be proven. In addition, other studies on girls treated in childhood with GnRH analogs for CPP have demonstrated normal BMI, body composition and ovarian function during early adulthood and no increase in PCOS frequency $(21,39)$.

Our systematic review had other limitations, with the main one being related to the study design.
Without randomization, we could not evaluate any unknown factor that would interfere with the outcome results. However, because of parents' concerns about possible adverse events of a new intervention in their children, we must consider the fact that clinical trials in children are observed less frequently in the literature. For this reason, it has been common for the control group to comprise patients whose parents refuse intervention. No study evaluated other important outcomes, such as quality of life and psychosocial impact related to EP or GnRH analog therapy.

In our registered protocol, we informed that we would include observational studies in the absence of experimental studies. As we did not find large and well-conducted randomized studies to result in a high or moderate quality of evidence, we combined the results of experimental studies with those of the single observational study available in the literature and that met our eligibility criteria (8).

Two published systematic reviews exist regarding the effectiveness of $\mathrm{GnRH}$ analogs in improving $\mathrm{AH}$ in girls. In 2014, Li et al. (40) aimed to evaluate the effect of GnRH therapy with and without added growth hormone $(\mathrm{GH})$. They included five studies without GH; in two studies (also included in our review), the effect of GnRH treatment was compared with nontreatment in patients with EP $(2,16)$; in two studies on EP, the groups had different PAH $(31,36)$ and in one study, CPP was evaluated (37). With moderate heterogeneity $\left(I^{2}=54.23 \%\right)$, their overall analysis revealed a significant difference in $\mathrm{AH}$ and $\mathrm{PAH}$, favoring $\mathrm{GnRH}$ therapy. However, of the five studies included in that meta-analysis, three reported no difference between the groups and in only the two studies that favored GnRH treatment, girls from the intervention and control groups had different prognoses regarding $\mathrm{AH}$ or had pubertal development before 7 years of age $(31,37)$. However, they did not include the four studies that were included in our review $(8,13,14,15)$.

The second published systematic review evaluated only patients with EP (41). However, the investigators included controlled (five were also included in our review $(8,2,13,15,16))$ and uncontrolled studies and concluded that GnRH analogs did not widely change the growth outcome. Compared with our review, in the previously published review, the invesigators only searched for eligible studies in PubMed and included only studies published in English (they did not include the study conducted by Llop-Vinolas et al. (14)). They did not present a previously registered protocol, they did not apply a tool for assessing the risk of bias in the included studies, and they did not 


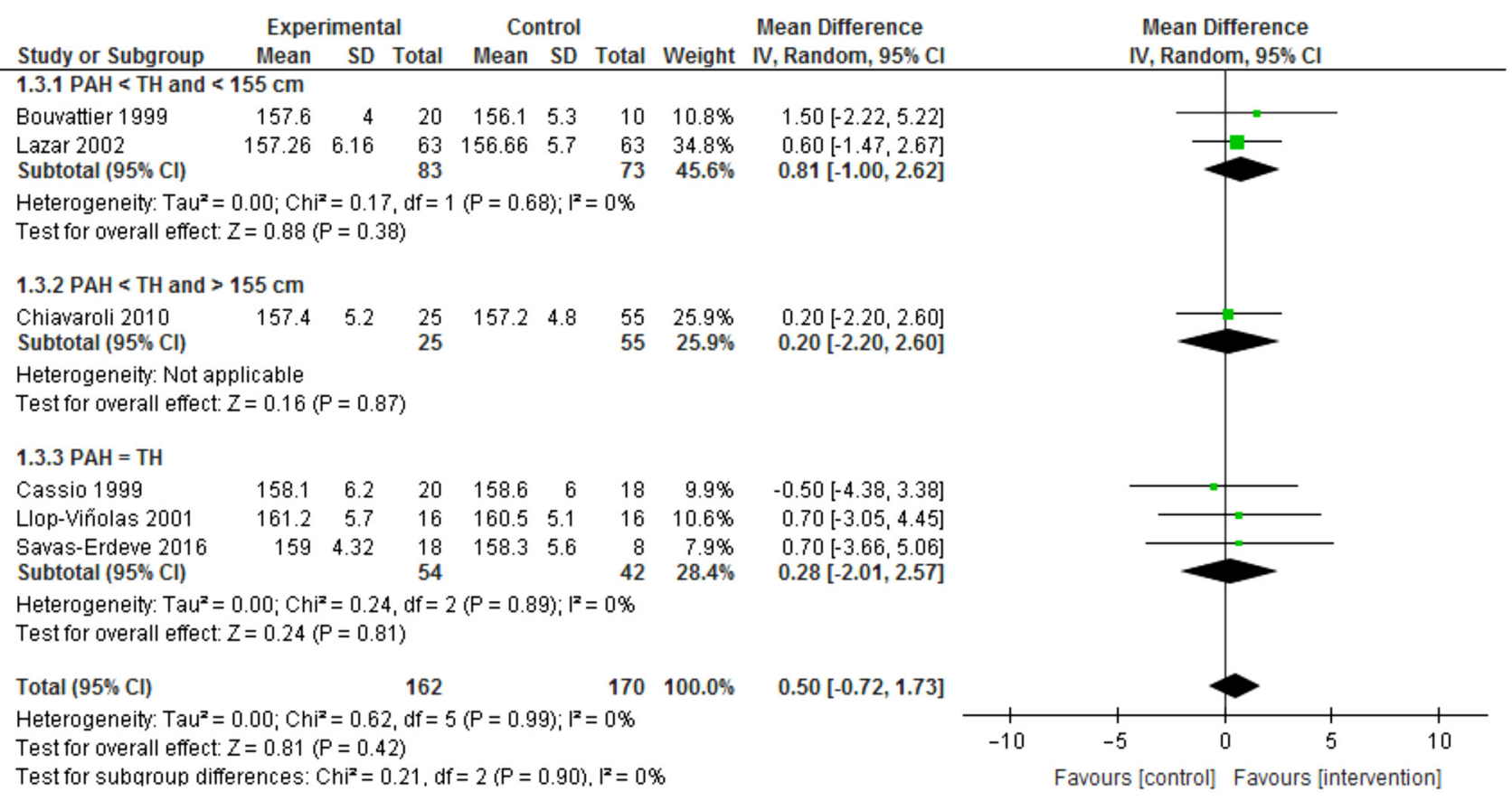

\section{Figure 3}

Meta-analysis of $\mathrm{AH}$ with sub-group analysis according to the predicted $\mathrm{AH}$ (PAH) and TH showing no difference between the groups. Experimental: GnRH analog treatment; Control: no treatment. A full colour version of this figure is available at https:// doi.org/10.1530/EJE-18-0473.

evaluate the quality of evidence of their results. In the meta-analysis, they plotted the outcome $\mathrm{AH}$ as an s.D. score. As the unit of $\mathrm{AH}$ is intuitively interpretable $(\mathrm{cm})$ and to promote easy comprehension among clinicians, we plotted the average AH of each group in each study, and MD between the intervention and control groups was presented in the meta-analysis. We also presented a metaanalysis of $\mathrm{AH}$ according to $\mathrm{PAH}$.

\section{Conclusion}

\section{Implications for practice}

We did not find any evidence from controlled experimental and observational studies that compared with no treatment, GnRH analog treatment increases $\mathrm{AH}$ in girls with EP independent of the prognosis of $\mathrm{AH}$ on baseline visit $(\mathrm{PAH} \leq \mathrm{TH})$.

\section{Implications for research}

As in experimental and observational studies, girls with EP achieved their TH independent of puberty blockade. We do not believe that new randomized studies with $\mathrm{GnRH}$ therapy will provide different results regarding $\mathrm{AH}$.
However, observational studies are needed for evaluating if EP has a negative impact on the quality of life and other psychosocial aspects of girls with this condition.

Supplementary data

This is linked to the online version of the paper at https://doi.org/10.1530/ EJE-18-0473.

Declaration of interest

The authors declare that there is no conflict of interest that could be perceived as prejudicing the impartiality of this study.

Funding

This research was partially supported by the São Paulo Research Foundation (FAPESP): Grant number: 2015/23447-6.

Acknowledgments

The authors thank Susan S Lindsey, Veronica L Nunes, Henrik Sadlowski and Tingxue Song for translating the articles published in languages other than English (French, German and Mandarin).

\section{References}

1 Mul D, Oostdijk W \& Drop SL. Early puberty in girls. Best Practice and Research: Clinical Endocrinology and Metabolism 200216 153-163. (https://doi.org/10.1053/beem.2001.0187) 
2 Cassio A, Cacciari E, Balsamo A, Bal M \& Tassinari D. Randomised trial of LHRH analogue treatment on final height in girls with onset of puberty aged 7.5-8.5 years. Archives of Disease in Childhood 1999 81 329-332. (https://doi.org/10.1136/adc.81.4.329)

3 Lebrethon MC \& Bourguignon JP. Management of central isosexual precocity: diagnosis, treatment, outcome. Current Opinion in Pediatrics 200012 394-399. (https://doi.org/10.1097/00008480-20000800000020)

4 Carel JC, Lahlou N, Roger M \& Chaussain JL. Precocious puberty and statural growth. Human Reproduction Update 200410 135-147. (https://doi.org/10.1093/humupd/dmh012)

5 Jaruratanasirikul S, Thongkum K, Krisaneepaiboon S \& Sriplung H. Girls with early puberty attain a near-final height similar to their target height. Journal of Pediatric Endocrinology and Metabolism 2011 24 339-345. (https://doi.org/10.1515/jpem.2011.005)

6 Wheeler MD. Physical changes of puberty. Endocrinology and Metabolism Clinics of North America 199120 1-14. (https://doi. org/10.1016/S0889-8529(18)30279-2)

7 Ehrhardt AA \& Meyer-Bahlburg HF. Idiopathic precocious puberty in girls: long-term effects on adolescent behavior. Acta Endocrinologica Supplementum 1986279 247-253. (https://doi.org/10.1530/ acta.0.112S247)

8 Lazar L, Kauli R, Pertzelan A \& Phillip M. Gonadotropin-suppressive therapy in girls with early and fast puberty affects the pace of puberty but not total pubertal growth or final height. Journal of Clinical Endocrinology and Metabolism 200287 2090-2094. (https:// doi.org/10.1210/jcem.87.5.8481)

9 Higgins JPTGreenS (editors). Cochrane Handbook for Systematic Reviews of Interventions, Version 5.1.0 [updated March 2011]. The Cochrane Collaboration, 2011. Available from www.handbook. cochrane.org

10 Moher D, Liberati A, Tetzlaff J, Altman DG \& PRISMA Group. Preferred reporting items for systematic reviews and meta-analyses: the PRISMA statement. BMJ 2009339 b2535. (https://doi. org/10.1136/bmj.b2535)

11 Wells GA, Shea B, O'Connell D, Peterson J, Welch V, Losos M \& Tugwell P. The Newcastle-Ottawa Scale (NOS) for Assessing the Quality of Nonrandomised Studies in Meta-Analyses. Canada: Department of Epidemiology and Commuunity Medicine, University of Ottawa. (available at: http://www.ohri.ca/programs/clinical_epidemiology/ oxford.asp). Accessed on 2 February 2018.

12 Guyatt G, Oxman AD, Akl EA, Kunz R, Vist G, Brozek J, Norris S, Falck-Ytter Y, Glasziou P, DeBeer H et al. GRADE guidelines: 1. Introduction-GRADE evidence profiles and summary of findings tables. Journal of Clinical Epidemiology 201164 383-394. (https://doi. org/10.1016/j.jclinepi.2010.04.026)

13 Chiavaroli V, Liberati M, D'Antonio F, Masuccio F, Capanna R, Verrotti A, Chiarelli F \& Mohn A. GNRH analog therapy in girls with early puberty is associated with the achievement of predicted final height but also with increased risk of polycystic ovary syndrome. European Journal of Endocrinology 2010163 55-62. (https://doi. org/10.1530/EJE-09-1102)

14 Llop-Viñolas D, Vizmanos-Lamotte B, Aresté-Piztzalis A, Fernández-Ballart J \& Martí-Henneberg C. Treatment with LHRH analogues in girls with precocious puberty does not improve final height. Longitudinal study compared with a control group. Medicina Clínica 2001117 124-128. (https://doi.org/10.1016/ S0025-7753(01)72039-8)

15 Savaş-Erdeve Ş, Şıklar Z, Hacıhamdioğlu B, Kocaay P, Çamtosun E, Öcal G \& Berberoğlu M. Gonadotropin-releasing hormone analogue treatment in females with moderately early puberty: no effect on final height. Journal of Clinical Research in Pediatric Endocrinology 2016 8 211-217. (https://doi.org/10.4274/jcrpe.2356)

16 Bouvattier C, Coste J, Rodrigue D, Teinturier C, Carel JC, Chaussain JL \& Bougnères PF. Lack of effect of GnRH agonists on final height in girls with advanced puberty: a randomized long-term pilot study. Journal of Clinical Endocrinology and Metabolism 199984 3575-3578. (https://doi.org/10.1210/jcem.84.10.6032)

17 Carel JC \& Chaussain JL. Gonadotropin releasing hormone agonist treatment for central precocious puberty. Hormone Research 199951 (Supplement 3) 64-69. (https://doi.org/10.1159/000053164)

18 Carel JC, Roger M, Ispas S, Tondu F, Lahlou N, Blumberg J \& Chaussain JL. Final height after long-term treatment with triptorelin slow release for central precocious puberty: importance of statural growth after interruption of treatment. French study group of Decapeptyl in Precocious Puberty. Journal of Clinical Endocrinology and Metabolism 199984 1973-1978. (https://doi.org/10.1210/ jcem.84.6.5647)

19 Poomthavorn P, Suphasit R \& Mahachoklertwattana P. Adult height, body mass index and time of menarche of girls with idiopathic central precocious puberty after gonadotropin-releasing hormone analogue treatment. Gynecological Endocrinology 201127 524-528. (https://doi.org/10.3109/09513590.2010.507289)

20 Park HK, Lee HS, Ko JH, Hwang IT, Lim JS \& Hwang JS. The effect of gonadotrophin-releasing hormone agonist treatment over 3 years on bone mineral density and body composition in girls with central precocious puberty. Clinical Endocrinology 201277 743-748. (https:// doi.org/10.1111/j.1365-2265.2012.04418.x)

21 Magiakou MA, Manousaki D, Papadaki M, Hadjidakis D, Levidou G, Vakaki M, Papaefstathiou A, Lalioti N, Kanaka-Gantenbein C, Piaditis $\mathrm{G}$ et al. The efficacy and safety of gonadotropin-releasing hormone analog treatment in childhood and adolescence: a single center, long-term follow-up study. Journal of Clinical Endocrinology and Metabolism 201095 109-117. (https://doi.org/10.1210/jc.20090793)

22 Adan L, Chemaitilly W, Trivin C \& Brauner R. Factors predicting adult height in girls with idiopathic central precocious puberty: implications for treatment. Clinical Endocrinology 200256 297-302. (https://doi.org/10.1046/j.1365-2265.2002.01488.x)

23 Wolters B, Lass N \& Reinehr T. Treatment with gonadotropinreleasing hormone analogues: different impact on body weight in normal-weight and overweight children. Hormone Research in Paediatrics 201278 304-311. (https://doi.org/10.1159/000346145)

24 Traggiai C, Perucchin PP, Zerbini K, Gastaldi R, De Biasio P \& Lorini R. Outcome after depot gonadotrophin-releasing hormone agonist treatment for central precocious puberty: effects on body mass index and final height. European Journal of Endocrinology 2005 153 463-464. (https://doi.org/10.1530/eje.1.01975)

25 Feuillan PP, Jones JV, Barnes K, Klein KO \& Cutler GB Jr. Follow-up of children and young adults after GnRH-agonist therapy or central precocious puberty. Journal of Endocrinological Investigation 200124 734-736. (https://doi.org/10.1007/BF03343918)

26 Lanes R, Soros A \& Jakubowicz S. Accelerated versus slowly progressive forms of puberty in girls with precocious and early puberty. Gonadotropin suppressive effect and final height obtained with two different analogs. Journal of Pediatric Endocrinology and Metabolism 200417 759-766. (https://doi.org/10.1515/ JPEM.2004.17.5.759)

27 Yuan JN, Liang L, Cai XD, Li Z, Bai M \& Gu CP. Impact of gonadotropin-releasing hormone analogs on body mass index in girls with idiopathic central precocious puberty: a long-term follow-up study. Chinese Journal of Contemporary Pediatrics 201113 896-899.

28 Couto-Silva AC, Adan L, Trivin C \& Brauner R. Adult height in advanced puberty with or without gonadotropin hormone releasing hormone analog treatment. Journal of Pediatric Endocrinology and Metabolism 200215 297-305. (https://doi.org/10.1515/ JPEM.2002.15.3.297)

29 Shiasi Arani K \& Heidari F. Gonadotropin-releasing hormone agonist therapy and obesity in girls. International Journal of Endocrinology and Metabolism 201513 e23085. (https://doi. org/10.5812/ijem.23085v2) 
30 Léger J, Reynaud R \& Czernichow P. Do all girls with apparent idiopathic precocious puberty require gonadotropin-releasing hormone agonist treatment? Journal of Pediatrics 2000137 819-825. (https://doi.org/10.1067/mpd.2000.109201)

31 Bertelloni S, Baroncelli GI, Sorrentino MC, Perri G \& Saggese G. Effect of central precocious puberty and gonadotropin-releasing hormone analogue treatment on peak bone mass and final height in females. European Journal of Pediatrics 1998157 363-367. (https://doi. org/10.1007/s004310050831)

32 Kreiter M, Burstein S, Rosenfield RL, Moll GW, Jr, Cara JF, Yousefzadeh DK, Cuttler L \& Levitsky LL. Preserving adult height potential in girls with idiopathic true precocious puberty. Journal of Pediatrics 1990117 364-370. (https://doi.org/10.1016/S00223476(05)81074-1)

33 Gomez F, Pico AM, Vargas F \& Mauri M. Improvement of expected and final height in girls with central precocious puberty treated with gonadotropin releasing hormone analogues. Medicina Clínica 1996 107 681-684.

34 Brauner R, Adan L, Malandry F \& Zantleifer D. Adult height in girls with idiopathic true precocious puberty. Journal of Clinical Endocrinology and Metabolism 199479 415-420. (https://doi. org/10.1210/jcem.79.2.8045957)

35 Antoniazzi F, Cisternino M, Nizzoli G, Bozzola M, Corrias A, De Luca F, De Sanctis C, Rigon F, Zamboni G, Bernasconi S et al. Final height in girls with central precocious puberty: comparison of two different luteinizing hormone-releasing hormone agonist treatments. Acta Paediatrica 199483 1052-1056. (https://doi. org/10.1111/j.1651-2227.1994.tb12984.x)
36 Stasiowska B, Vannelli S \& Benso L. Final height in sexually precocious girls after therapy with an intranasal analogue of gonadotrophin-releasing hormone (buserelin). Hormone Research 199442 5. (https://doi.org/10.1159/000184136)

37 Kauli R, Galatzer A, Kornreich L, Lazar L, Pertzelan A \& Laron Z. Final height of girls with central precocious puberty, untreated versus treated with cyproterone acetate or GnRH analogue. A comparative study with re-evaluation of predictions by the BayleyPinneau method. Hormone Research 199747 54-61. (https://doi. org/10.1159/000185432)

38 Bayley N \& Pinneau SR. Tables for predicting adult height from skeletal age: revised for use with the Greulich-Pyle hand standards. Journal of Pediatrics 195240 423-441. (https://doi.org/10.1016/ S0022-3476(52)80205-7)

39 Pasquino AM, Pucarelli I, Accardo F, Demiraj V, Segni M \& Di Nardo R. Long-term observation of 87 girls with idiopathic central precocious puberty treated with gonadotropin-releasing hormone analogs: impact on adult height, body mass index, bone mineral content, and reproductive function. Journal of Clinical Endocrinology and Metabolism 200893 190-195. (https://doi.org/10.1210/jc.2007-1216)

40 Li P, Li Y \& Yang CL. Gonadotropin releasing hormone agonist treatment to increase final stature in children with precocious puberty: a meta-analysis. Medicine 201493 e260. (https://doi. org/10.1097/MD.0000000000000260)

41 Bertelloni S, Massart F, Miccoli M \& Baroncelli GI. Adult height after spontaneous pubertal growth or GnRH analog treatment in girls with early puberty: a meta-analysis. European Journal of Pediatrics 2017176 697-704. (https://doi.org/10.1007/s00431-017-2898-8)

Received 6 June 2018

Revised version received 11 September 2018

Accepted 24 September 2018 